\title{
Investigation of Affecting Parameters on Heap Leaching Performance and Reducing Acid Consumption of Low Grade Oxide-Sulfide Copper Ore
}

\author{
Mohsen Azmayandeh ${ }^{1,}$, , Valeh Aghazadeh ${ }^{1}$, Hadi Abdollahi $^{2}$ \\ ${ }^{1}$ School of Mining, College of Engineering, Sahand University of Technology, Tabriz, Iran \\ ${ }^{2}$ School of Mining, College of Engineering, University of Tehran, Tehran, Iran \\ Email address: \\ M_azmayandeh@sut.ac.ir (M. Azmayandeh) \\ ${ }^{*}$ Corresponding author
}

\section{To cite this article:}

Mohsen Azmayandeh, Valeh Aghazadeh, Hadi Abdollahi. Investigation of Affecting Parameters on Heap Leaching Performance and Reducing Acid Consumption of Low Grade Oxide-Sulfide Copper Ore. International Journal of Mineral Processing and Extractive Metallurgy. Vol. 2, No. 4, 2017, pp. 40-45. doi: 10.11648/j.ijmpem.20170204.11

Received: May 26, 2017; Accepted: July 26, 2017; Published: August 24, 2017

\begin{abstract}
Heap leaching method is known as cheap method for copper extraction. Presence of clay and acid consumer waste minerals are the most critical issues because they may bring out the process from economic mode. For reduce acid consumption and increasing copper extraction in heap leaching method, about 3 tons sample was taken randomly from different low grade zones. After homogenization and spelling into small parts, bottle roll tests were carried out to achieve maximum copper recovery and acid consumption in a short time at $\mathrm{pH}=1,1.1$ and 1.2. Maximum copper recovery were 60.8, 60.2 and $60.1 \%$, respectively. Also acid consumption were 107.30, 99.90 and $93.23 \mathrm{~kg} / \mathrm{t}$ of ore, respectively. After diagnostic tests, nine columns with dimension $2 \mathrm{~m}$ height and $15 \mathrm{~cm}$ diameter were filled by $0.5,1$ and 1.5 inches ore. Columns were irrigated with 7,9 and $11 \mathrm{~g} / 1$ as acid solution concentration at flow rates of 7, 11 and $151 / \mathrm{m}^{2} * \mathrm{~h}$ for 63 days. Results showed that there are high correlation between copper and iron recoveries. Copper recovery changed from $25.5 \%$ to $58.9 \%$ while iron recovery changed from $4.7 \%$ to $15.2 \%$. Acid consumption were achieved between 18 to $54 \mathrm{~kg}$ per ton of ore. Acid solution concentration and irrigation flow rate are the most important parameters on the copper and iron recoveries. By increasing of leaching period Copper extraction will increase, but acid will be waste more. Copper and iron recoveries were increased with increasing the acid solution concentration and irrigation flow rate but Increasing in amount of acid consumption does not increase copper extraction inevitably. Irrigation flow rate of acid solution has significant effect on acid consumption. With decreasing the ore particle size, both of copper recovery and acid consumption were increased.
\end{abstract}

Keywords: Copper Oxide Heap Leaching, Bottle Rolling Test, Column Tests, Copper and Iron Recoveries, Acid Sulfuric Consumption

\section{Introduction}

Sarcheshmeh copper complex is located in 160 kilometers south-west of Kerman and 50 kilometers south of Rafsanjan and the central area of the Zagros Mountains [1]. Copper production at this complex is done by pyro-metallurgy and hydrometallurgy methods [2]. Following decline of highgrade copper reserves and increasing global demand of copper metal caused that hydrometallurgical and heap leaching method has been designed and used. These method, in addition to being less pollution to the environment is included, provides the extraction of copper from low grade oxide and sulfide ores [3]. Heap leaching has been demonstrated as a viable and low cost approach to open-pit mining operations with low-grade and complex run of mine (ROM) ores, agglomerated flotation tailings and also for the treatment of coarse rejects from semi-autogenous grinding (SAG) circuits [4]. Modern heap leaching might be defined as a controlled process whereby ore is stacked in thin lifts (under $10 \mathrm{~m}$ in most cases), usually crushed and often agglomerated, on a carefully prepared containment system and irrigated in a controlled manner with a solvent to extract the optimum amount of the target mineral [5]. Low capital 
and operating costs and simple atmospheric leach process make heap leaching suitable for low grade ores and small deposits. Disadvantages include low recoveries, long rampup times, large footprint and acid-mine drainage of wastes [6]. Ore and gangue mineralogy is probably the most important parameter affecting the operating costs and recoveries [7]. Heap leaching issues are classified in three categories: 1) Mineralogy handling include: crushing, agglomeration, heaping and heap configuration, 2) Solution handling include: irrigation configuration, solution application, irrigation media and rates, forms of solution collection, water consumption, 3) Operating aspects such as drag of fines, flooding and solution channeling, heap erosion, air injection and others [8]. Factors that may make ores unsuitable for heap leaching are poor percolation due to the presence of swelling clays, and high gangue acid consumption [6]. Percolation can be improved by agglomerating with acid binder, and by minimizing ore compaction during stacking heap lifts [9]. Silicate and iron oxide gangue minerals such as limonite consume sulfuric acid during initial reaction with acid [10]. Increasing acid concentration in solution caused increasing the acid consumption and consequently dissolve gangue minerals without significant effect on copper extraction [11]. The economics of heap leaching are strongly governed by the trade-off between the slow rate and limited extent of leaching from large particles and the cost of crushing finer [12].

Most affecting parameters on copper extraction in heap leaching method are ore and gangue mineralogy, size distribution, leaching time, percolation, irrigation flow rate, temperature and concentration that some of them are uncontrollable [13].

In this study effect of ore size distribution, acid concentration in solution and irrigation flow rate of solution has been investigated on copper extraction and acid consumption in column and bottle roll tests for Sarcheshmeh copper mine low grade oxide-sulfide ore.

\section{Material and Methods}

\subsection{Sample Preparation and Analyses}

For metallurgical test works, approximately 3 tons ore was taken from low grade zones of Sarcheshmeh copper mine for preparing representative sample. After homogenizing and splitting into smaller parts, 3 parts about $300 \mathrm{~kg}$ were selected randomly and crushed below than 1.5, 1 and 0.5 inches. Then some samples from 0.5 inch fraction were taken and sent to XRF, XRD and mineralogical analyses. Table 1 shows result of XRF analyses that analyzed by XRF Philips PW 1480 instrument.

Table 1. XRF analysis.

\begin{tabular}{llllllll}
\hline Element/compound & $\mathrm{Cu}$ & $\mathbf{C u}$ & $\mathrm{Fe}$ & $\mathrm{S}$ & $\mathrm{Mo}$ & $\boldsymbol{A L}_{\mathbf{2}} \boldsymbol{O}_{3}$ & $\mathbf{S i O}_{\mathbf{2}}$ \\
\hline Content (\%) & 0.83 & 0.51 & 6.25 & 3.90 & 0.002 & 16.90 & 55.36 \\
\hline
\end{tabular}

Mineralogy analysis showed that chalcopyrite is the major phase of the copper sulfide mineral and chalcocite is the minor phase. Also, other minerals such as pyrite, limonite, hematite and magnetite were distinguished in the representative sample. It was determined that 0.51 percent of copper is presented in oxide minerals. XRD analysis is presented in Table 2.

Table 2. Countitative XRD analysis.

\begin{tabular}{llllll}
\hline Phases & Clinochlore & Muscovite & Quartz & Pyrite & Albite \\
\hline Content (\%) & 17 & 40 & 24 & 8 & 12 \\
\hline
\end{tabular}

Chalcopyrite, chalcocite and pyrite were identified in polished sections images. The polished section of sample are shown in Figure 1.
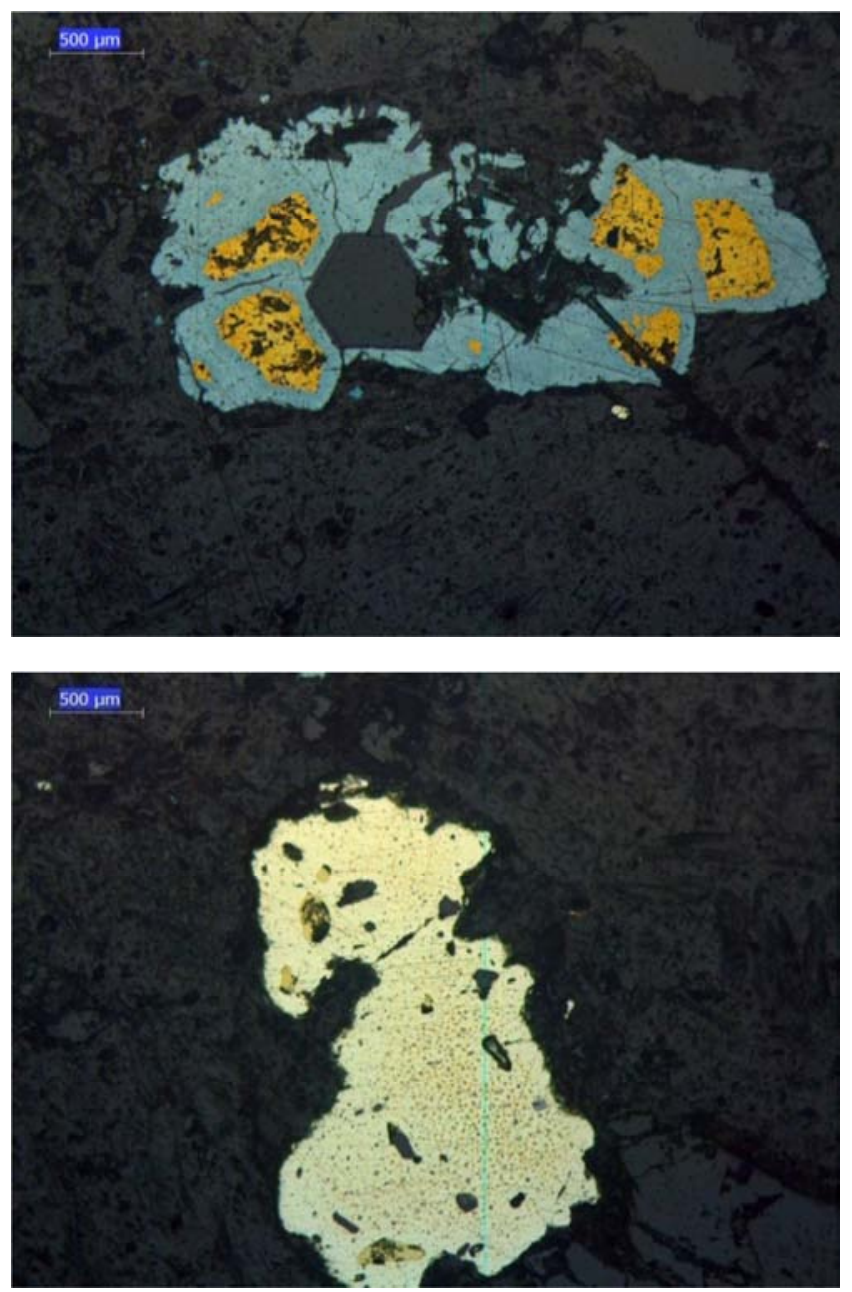

Figure 1. Polished section of ore sample, blue: chalcocite, golden: chalcopyrite, yellow: pyrite.

\subsection{Battle Roll Tests}

Bottle roll tests were conducted on a bottle roller apparatus under procedure that sowed in table 2. These experiments provide initial information for copper extraction and acid consumption in a short time [14]. Acid consumption are normally overestimated in rolling bottles, hence the acid consumption results should be considered as semiquantitative [6]. Bottle roll tests were carried out at 7 days in 3 various $\mathrm{pH}(\mathrm{pH}=1.2,1.1$ and 1$)$. One of tests was repeated 
to ensure the accuracy. The parameters and conditions for bottle roll tests are presented in Table 3 .

Table 3. Parameters and conditions for bottle roll tests.

\begin{tabular}{llllll}
\hline Test number & Solid weight (gr) & Solution volume (cc) & Total volume (cc) & Rotational speed (RPM) & pH \\
\hline 1 & 105 & 700 & 735 & 60 & 1.2 \\
2 & 105 & 700 & 738 & 60 & 1.1 \\
3 & 105 & 700 & 737 & 60 & 1 \\
4 & 105 & 700 & 736 & 60 & 1.2 \\
\hline
\end{tabular}

Bottles' $\mathrm{pH}$ were measured every day and were fixed at the specified value by adding acid. Addition of acid were continued until the $\mathrm{pH}$ was fixed at the specified value. Because $\mathrm{pH}$ was remained constant during the test, the amount of acid consumed is equivalent to acid added. Copper and iron recoveries were calculated by PLS analysis that has been done by Atomic Absorption Spectroscopy.

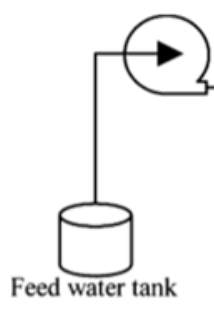

Peristaltic pump

\subsection{Column Tests}
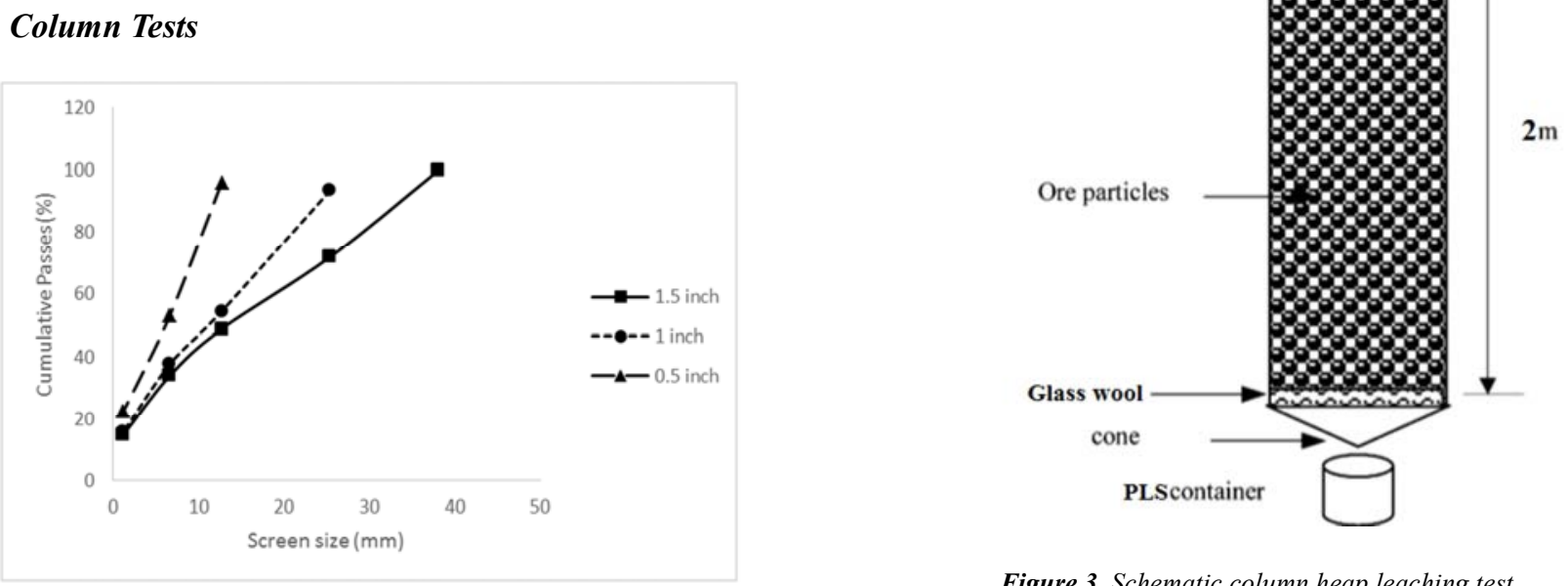

Figure 2. Ore size distribution in columns.

Figure 3. Schematic column heap leaching test.

Table 4. The conditions of nine column tests.

\begin{tabular}{|c|c|c|c|c|c|}
\hline \multirow{2}{*}{ Column Number } & \multirow{2}{*}{ Ore weight (kg) } & \multirow{2}{*}{ Max particle size (inch) } & \multirow{2}{*}{ Acid concentration (g/l) } & \multicolumn{2}{|c|}{ Irrigation rate } \\
\hline & & & & I/h. $m^{2}$ & $\mathrm{~mm} / \mathbf{m i n}$ \\
\hline A1 & 56 & 0.5 & 7 & 7 & 1.75 \\
\hline A2 & 53 & 0.5 & 9 & 11 & 2.75 \\
\hline A3 & 54 & 0.5 & 11 & 15 & 3.75 \\
\hline A4 & 54 & 1 & 7 & 11 & 2.75 \\
\hline A5 & 57 & 1 & 9 & 15 & 3.75 \\
\hline A6 & 57.5 & 1 & 11 & 7 & 1.75 \\
\hline A7 & 62 & 1.5 & 7 & 15 & 3.75 \\
\hline A8 & 60 & 1.5 & 9 & 7 & 1.75 \\
\hline A9 & 60 & 1.5 & 11 & 11 & 2.75 \\
\hline
\end{tabular}

Column leach tests are the most important part of the metallurgical test work program. The two key results can be obtained from the column tests which are the maximum copper extraction and acid consumption under percolationcontact mode [15]. Leaching tests were carried out using nine columns with dimension $2 \mathrm{~m}$ height and $15 \mathrm{~cm}$ diameter in open-cycle. Column height must be bigger than 10 times of the column diameter and it must be bigger than five times of largest particle diameter. These ratios are considered for remove channeling flow in column [16]. Literature review showed that ore size distribution, acid concentration and irrigation flow rate are the most controllable parameters on copper heap leaching. After diagnostic tests, nine columns were filled by $0.5,1$ and 1.5 inches ore. Figure 2 shows ore size distribution in columns.

Columns were irrigated with 7,9 and $11 \frac{g}{L}$ as acid solution concentration at flow rates of 7, 11 and $15 \mathrm{~L} / \mathrm{m}^{2} * \mathrm{~h}$ for 63 days. The conditions of nine column tests are presented in Table 4 and figure 3 shows schematic column heap leaching test.

\section{Results and Discussion}

\subsection{Bottle Roll Tests}

Results showed acid consumption was changed from 92.23 
to $107.3 \mathrm{~kg}$ per ton of ore and maximum copper recovery was $60.8 \%$ for total copper. The residuals for bottle roll tests and their results are presented in Table 5.

Table 5. The residuals for bottle roll tests and their results.

\begin{tabular}{llllllll}
\hline Number & pH & Solution Volume (cc) & Solid Weight (gr) & Cu Recovery (\%) & Fe Recovery (\%) & Acid consumption (cc) & Acid consumption (kg/t) \\
\hline 1 & 1.2 & 716 & 101.0 & 60.10 & 6.95 & 7.6 & 107.30 \\
2 & 1.1 & 728 & 99.4 & 60.20 & 7.63 & 8.1 & 9.7 \\
3 & 1 & 725 & 100.0 & 60.80 & 8.85 & 7.5 & 93.23 \\
4 & 1.2 & 728 & 100.6 & 60.15 & 7.15 & 92.50 \\
\hline
\end{tabular}

The acid consumption was reduced over time. By advancement of minerals dissolution, the less acid is required to dissolve the remaining minerals and some acid is produced during the reactions. Reactions 1 and 2 shows acid production in dissolution copper minerals [17].

$$
\begin{gathered}
\mathrm{Cu}_{2} \mathrm{~S}+2 \mathrm{Fe}\left(\mathrm{SO}_{4}\right)_{3} \rightarrow 2 \mathrm{CuSO}_{4}+4 \mathrm{FeSO}_{4}+S^{\circ} \\
S^{\circ}+1.5 \mathrm{O}_{2}+\mathrm{H}_{2} \mathrm{O} \rightarrow \mathrm{H}_{2} \mathrm{SO}_{4}
\end{gathered}
$$

The generation of acid in bottles and the reduction of soluble minerals by reaction advancement caused to reduce acid consumption over time. Figure 4 shows the consumption of acid for each bottle.

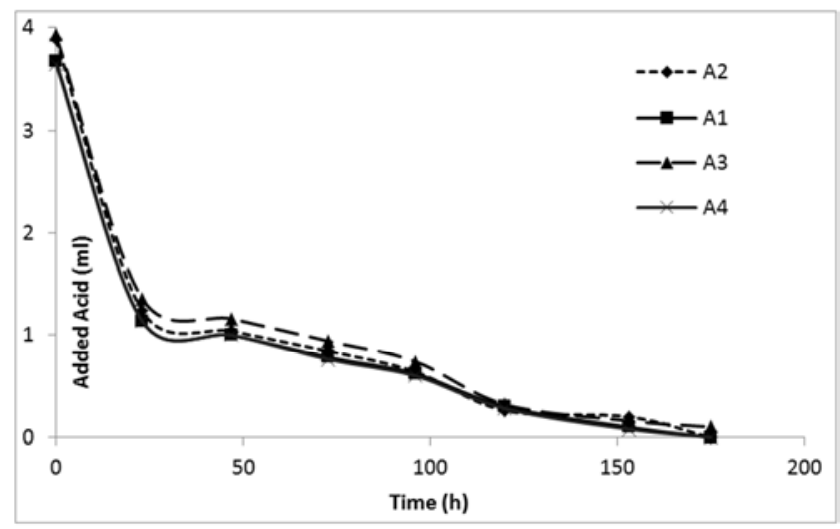

Figure 4. Acid consumption in bottle roll tests.

\subsection{Column Tests}

\subsubsection{Copper Recovery}

Column tests results showed copper recovery changed from $25.5 \%$ to $58.9 \%$. Monitoring the daily copper concentration in PLS showed column number A6 with ${ }_{7} \mathrm{~L} / \mathrm{m}^{2} * h$ irrigation flow rate and $11^{g} / \mathrm{L}$ acid concentration in solution has maximum copper concentration in PLS and column A7 has minimum concentration of copper by 15 $L / m^{2} * h$ irrigation flow rate and $7^{g} / L$ acid concentration in solution. Maximum Copper recovery was obtained at 11 $g / L$ acid concentration, $15^{L} / m^{2} * h$, irrigation flow rate and ore particle size below than 0.5 inch. Cumulative copper recovery in columns are shown in Figure 5.

Study of table 5 and compare it with table 3 shows that increasing of irrigation flow rate and acid concentration in solution, caused increasing copper and iron recovery. Also reducing of ore size distribution has same effect on copper and iron recovery that caused for increasing contact surface between ore and solution. There is no significant correlation between copper recovery and volume of irrigation solution. For example columns number A3 and A5 by irrigation same volume of solution (approximately 282 Liters) has $58.9 \%$ and $48.8 \%$ copper recovery respectively and columns number A2 and A4 by irrigation same volume of solution (approximately 195 liters) has $45.8 \%$ and $30.9 \%$ copper recovery respectively.

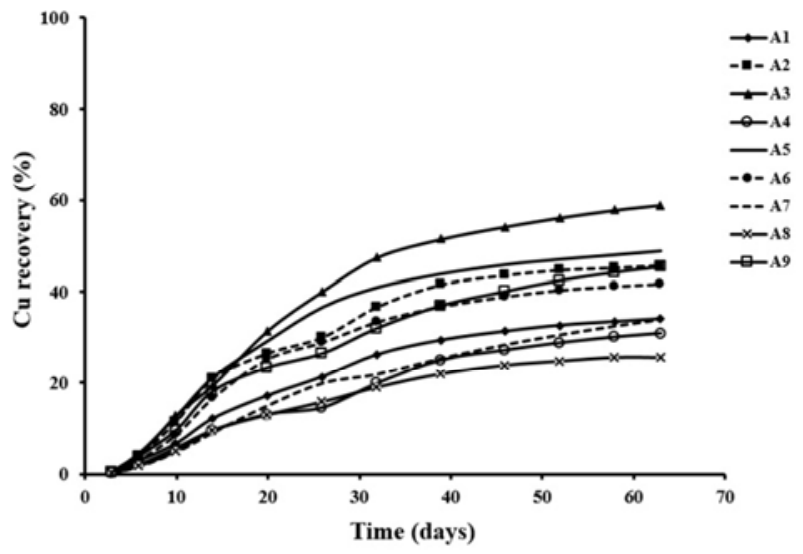

Figure 5. Cumulative total copper recovery in columns.

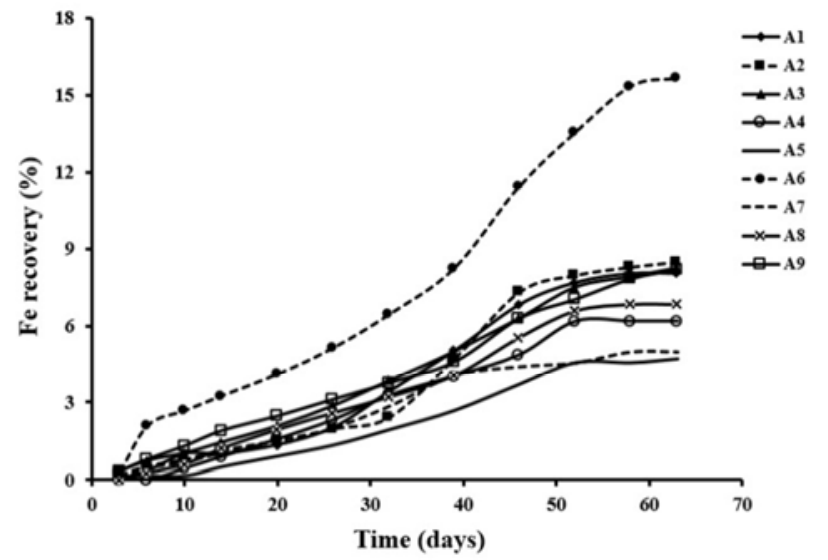

Figure 6. Cumulative iron recovery in columns.

\subsubsection{Iron Recovery}

Presence of iron sulfate in solution increased copper recovery in heap leaching of copper ores [18]. The dissolution reactions under atmospheric conditions can be written as equation 3 and 4 for Chalcocite and Covellite, respectively [19]. Furthermore, increase of iron dissolution waste acid in the process. 


$$
\begin{gathered}
\mathrm{Cu}_{2} \mathrm{~S}+2 \mathrm{Fe}\left(\mathrm{SO}_{4}\right)_{3} \rightarrow 2 \mathrm{CuSO}_{4}+4 \mathrm{FeSO}_{4}+\mathrm{S}^{\circ} \\
\mathrm{CuS}+\mathrm{Fe}\left(\mathrm{SO}_{4}\right)_{3} \rightarrow \mathrm{CuSO}_{4}+2 \mathrm{FeSO}_{4}+S^{\circ}
\end{gathered}
$$

Results showed there are high correlation between copper and iron recoveries. Iron concentration was increased in PLS after 35 days treatment whereas iron recovery changed from $4.72 \%$ to $15.64 \%$. Cumulative iron recovery in columns are demonstrated in Figure 6.

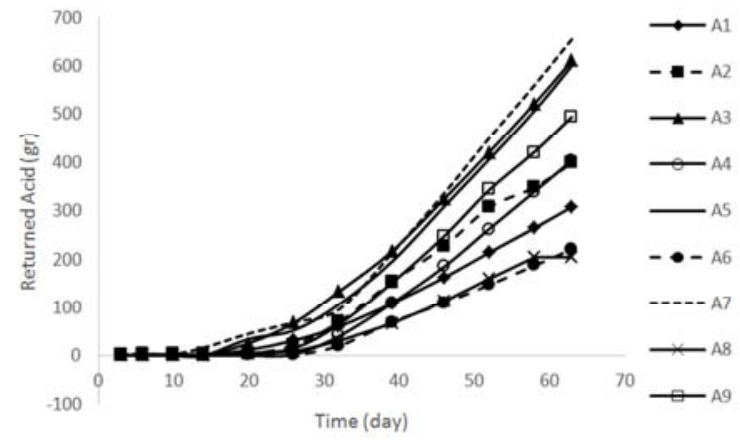

Figure 7. Comulative returned acid in columns.

\subsubsection{Acid Consumption}

Acid consumption in copper heap leaching is related to gunge mineralogy more than other factors. Silicate and iron oxide gangue minerals such as limonite consume sulfuric acid during initial reactions. Limonite consumes acid by breakdown to ferric ions in solution [20]. Silicate minerals consume acid by breakdown to a wide range of soluble solution products. K-feldspar, Na-feldspar, Ca-plagioclase and Biotite breakdown to Ortho-silicic acid, $\mathrm{H}_{4} \mathrm{SiO}_{4}$, and various metal cations such as $\mathrm{Na}^{+}, \mathrm{K}^{+}, \mathrm{Na}^{2+}, \mathrm{Ca}^{2+}, \mathrm{Fe}^{2+}$, $\mathrm{Fe}^{3+}$ and $\mathrm{Mg}^{2+}$ [21].

Acid consumption in bottle roll test is considered as semi quantitative. To achieve real acid consumption, column leaching tests are conducted. Maximum acid consumption in column leaching tests is about $40 \%$ of acid consumption in bottle roll tests [16]. The results of column test presented in Table 6.

Also it was defined there is no significant relation between acid consumption and copper recovery. Column number A1 by consumption 18.53 kilograms acid has $34 \%$ copper recovery whereas column number A8 by consumption 20.47 kilograms acid has $25.5 \%$ copper recovery.

Table 6. The results about irrigation and acid consumption in column tests.

\begin{tabular}{llllll}
\hline Column number & copper recovery & Iron recovery & $\begin{array}{l}\text { Volume of irrigated } \\
\text { solution (L) }\end{array}$ & Acid consumption (kg/t) & $\begin{array}{l}\text { Acid consumption } \\
\text { (ton/ton copper) }\end{array}$ \\
\hline A1 & 34 & 8.03 & 149 & 18.62 & 2.94 \\
A2 & 45.8 & 8.49 & 191.4 & 31.9 & 4.40 \\
A3 & 58.9 & 8.25 & 282.9 & 54.56 & 8.47 \\
A4 & 30.9 & 6.17 & 195.5 & 25.85 & 4.81 \\
A5 & 48.8 & 4.72 & 282.3 & 47.05 & 9.63 \\
A6 & 41.7 & 15.64 & 148.7 & 28.44 & 3.72 \\
A7 & 34.0 & 4.97 & 265.4 & 29.96 & 9.03 \\
A8 & 25.5 & 6.83 & 136.5 & 20.47 & 3.36 \\
A9 & 45.5 & 8.19 & 198.7 & 36.42 & 5.45 \\
\hline
\end{tabular}

The amount of unused acid in columns is calculated and illustrated in Figure 7. After 35 days acid concentration was increased in PLS and also returned acid has grown at this time.

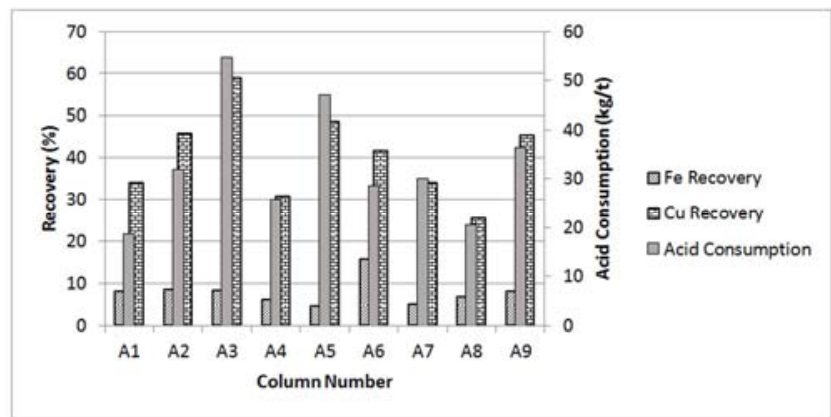

Figure 8. The correlation between copper and iron recoveries and acid consumption.

Monitoring the daily copper concentration in PLS showed copper concentration is low in columns with high irrigation flow rates. In contrast, high copper concentration in PLS obtained by columns with low irrigation flow rates. It can be concluded that at low irrigation flow rate, contact time is sufficient between minerals and sulfuric acid, then reaction is completed. So, increasing the irrigation flow rate reduced copper concentration in PLS. But high irrigation flow rate increase PLS volume and copper recovery. Reducing the particle size increases the contact surface between minerals and sulfuric acid which results the increase of copper recovery.

Comparing the graphs of iron recovery and returned acid showed that after 35 days, reaction between sulfuric acid and copper minerals was decreased and sulfuric acid wasted. For control iron concentration in PLS and prevent acid wasting, irrigation algorithm should be optimized, acid concentration in solution should be decreases and irrigation flow rate must be increase.

The correlation between copper and iron recoveries are shown in Figure 8. There are direct relationship between copper and iron recoveries. One of reasons could be probability dissolution of secondary copper minerals which have copper and iron. Also, there is no meaningful relation between copper and iron recoveries and acid consumption. 


\section{Conclusion}

1. The results of bottle roll and column leaching tests showed that acid consumption was high initially, then reduced and finally fixed at constant value.

2. Column test results conducted under various condition, there was high correlation between copper and iron recoveries.

3. Detailed study of copper, iron and acid concentration in PLS showed copper recovery was high initially and reduced over time. But iron recovery and returned acid were contrast. That means, their concentrations were low initially and then increased. Therefore, optimizing the irrigation algorithm resulted substantially reduction of iron concentration in PLS and prevented acid waste.

4. Increasing the concentration and irrigation flow rate had a positive effect on the recovery of copper. Reduction of size distribution increased copper and iron recoveries. In high irrigation flow rate, copper concentration in PLS decreased, but recovery increased for high volume of PLS.

5. Irrigation flow rate and acid concentration in solution had the most positive effects on acid consumption, respectively. Acid consumption reduced substantially by optimizing the acid irrigation algorithm.

6. Increasing of leaching period increases copper extraction, but acid being waste more.

7. Diagram of copper and iron recoveries and acid consumption did not show a significant relationship between them. This means that increase in acid consumption does not increase copper recovery.

\section{References}

[1] Ghaderian, SM., Ghotbi Ravandi, A., 2012. Accumulation of copper and other heavy metals by plants growing on Sarcheshmeh copper mining area, Iran. Journal of Geochemical Exploration, 123. Pages 25-32

[2] Massinaie, M., Oliazadeh, M., Seyed Bagheri, A., 2006. Biological copper extraction from melting furnaces dust of Sarcheshmeh copper mine. J. Mineral Processing. 81, 1, 58-62

[3] Norgate, T., Jahanshahi, S. 2010. Low grade ores - Smelt, leach or concentrate? J. Minerals Engineering. 23, 2. 65-73

[4] Hiskey, J. B., 1983 "Heap leaching practice at Alligator Ridge," Chapter 1, Current status of U. S. Gold and Silver Heap Leaching Operations, Heap and Dump Leaching practice, Proceedings from the 1983 SME Fall Meeting, October 19-21, 1983, Salt Lake City, pp. 1-7

[5] Breitenbach, A. J., Smith M, E. 2007. Geomembrane Raincoat Liners in the Mining Heap Leach Industry, J. Geosynthetics. 25, 2. 32-39

[6] Peacy, J., Xian-Jian, G., Robles, E. 2004. Copper hydrometallurgy: current status, preliminary economics, future direction and positioning versus smelting, Trans. J. Nonferrous Met. Soc. China, 14, 3. 560-568
[7] Aixiang, W., Shenghu, Y., Wenqing, Q., Jishan, L., Guanzhou, Q. 2009. The effect of preferential flow on extraction and surface morphology of copper sulphides during heap leaching, J. Hydrometallurgy. 95, 1-2. 76-81

[8] Ghorbani, Y., Franzidise, J. P., Peterson. J. 2016. Heap Leaching Technology-Current State, Innovations, and Future Directions: A Review. J. Mineral Processing and Extractive Metallurgy Review. 37, 2. 73-119

[9] Nikhil Dhawan, M., Safarzadeh, S., Miller, J. D., Michael, S., Moats, Raj K. Rajamani. 20013. Crushed ore agglomeration and its control for heap leach operations. J. Minerals Engineering, 41. 53-70

[10] Phanindra, K., Tolga D., Nikhil D., Xuming W., Lina C. L., Millera Ja, n D. 2011. Evaluation of stucco binder for agglomeration in the heap leaching of copper ore. J. Minerals Engineering, 24, 8. 886-893

[11] Lwambiyi, M., Maweja, K., Kongolo, K., Lwambiyi, N. M., Diyambi, M. 2009. Investigation into the heap leaching of copper ore from the Disele deposit. J. Hydrometallurgy. 98, 12. $177-180$.

[12] Ghorbani, Y., Becker, M., Mainza, A., Franzidis, J P. 2011. Large particle effect in chemical/biochemical heap leach processes-A review. J. Minerals Engineering. 24, 11. 11721184

[13] Khodadadi Darban, A., Koleyni, S MJ., Sheikhzadeh, Gh., Hasani, M. 2009. Mathematical Modelling and Development Software for leaching of Copper Oxide Minerals. J. Mining engineering. 4. 23-34

[14] Savov, G., Angelov, T., Tsekov, V., Grigorova, I., Nishkov I. 2011. Heap and Dump Leach Process at the Buchim Cooper Project - Metallurgical Testwork. XXII World Mining Congress, Vol. II, Istanbul, Turkey. 271-276

[15] Andrade Lima, L. R. P. 2006. Liquid axial dispersion and holdup in column leaching, J. Minerals Engineering. 19, 1.3747

[16] Dulliea. F. A. L. D. 1992. Porous Media: Fluid Transport and Pore Structure, B. Academic Press Inc. NewYork 1992

[17] Dreisinger, D. 2006. Copper leaching from primary sulfides: Options for biological and chemical extraction of copper. J. Hydrometallurgy. 83, 1-4. 10-20

[18] Schlitt, W. J. 1999. Hydrometallurgical treatment of Haib copper ore. J. south African institute of mining and metallurgy, 99, 2. 75-92

[19] Ferron, CJ. Riveros, P. A., Dixon, D. G. 2003. Leaching of secondary copper minerals using regenerated ferric sulfate Copper, VI: Hydrometallurgy of Copper, J. SGS MINERALS SERVICES, Technical Paper. 337-352

[20] Sherlock, E. J., Lawrence, R. W., Poulin, R. 1995. On the neutralization of acid rock drainage by carbonate and silicate minerals. J. Environmental Geology, 25, 1. 43-54

[21] Dopson, M., Halinen, AK, Rahunen, N., Boström, D., Sundkvist, JE. Riekkola-Vanhanen, M., Kaksonen, AH., Puhakka, JA. 2008. Silicate mineral dissolution during heap bioleaching. J. Biotechnol Bioeng. 99, 4. 811-820 